\title{
Experience of the New Zealand maternity care system by a group of Japanese women in one centre
}

\author{
Keiko Doering ${ }^{A} R M, M M \cdot$ Jean Patterson ${ }^{B} R M, P h D \cdot$ Christine Griffiths $^{B}$ RM, MA, PhD Candidate
}

${ }^{\text {A Corresponding }}$ Author: mwkeiko@ yahoo.co.jp

B School of Midwifery, Otago Polytechnic, New Zealand

\begin{abstract}
:
Objective: Birth is a social and cultural event, and giving birth in another country is a challenge for immigrant women. This article explores how some Japanese women experienced pregnancy, labour and birth care in New Zealand.

Methods: Thirteen Japanese women who had given birth in New Zealand participated in this study. Nine women were interviewed individually, and four women participated in a subsequent focus group. The conversations were analysed using thematic analysis.

Findings: The women had a range of experiences including some dilemmas and conflicts during their pregnancy, birth and postnatal care. This care differed from what they would expect had they given birth in Japan where care is shaped by the distinctly Japanese birth knowledge and culture. The women also experienced language and communication barriers even though they did not have problems with speaking English in their daily lives.

Discussion: The Japanese women's understanding of care in the New Zealand maternity system was influenced by the generally more relaxed image of New Zealand society, and issues emerged as a result of communication difficulties between the women and the care providers. This lack of communication was related to Japanese women's generally passive attitude, where conflict is avoided in the desire to maintain harmony and not cause offence.

Conclusion: When sharing information with Japanese women, care providers need to recognise that immigrant women hold knowledge from a different cultural history and maternity care system. Knowledge of these different cultural approaches to birth will enable better communication and help immigrant women make better informed decisions and receive more appropriate care throughout their childbearing experience in New Zealand.
\end{abstract}

Key words: Japanese women, maternity care system, New Zealand, Japanese culture

\section{INTRODUCTION}

Meanings, perceptions and experiences of childbearing vary and are strongly affected by women's own cultures (Callister, 1995; Callister, Semenic, \& Foster, 1999; Cheung, 2002; Jordan, 1980; Kartchner \& Callister, 2003; Liamputtong \& Naksook, 2003; Matsuoka, 1985). Thus, giving birth in a different culture adds a special challenge for women as they experience differences in systems, customs and perspectives.

In New Zealand, the population of Asians accounts for $11.8 \%$ of the total population (Statistics New Zealand, 2013). The population of Japanese immigrants (14,118 in 2013) has been rapidly increasing alongside other Asian ethnic groups, and the population increased nearly $20 \%$ over the last decade. However, their birth experiences have not been specifically documented until now. This article focuses on how the Japanese women in this study understood and experienced the differences in maternity care systems between the two countries when giving birth in New Zealand.

\section{STUDY DESIGN}

A qualitative research approach was chosen to give voice to the women's understanding of their experience. This was informed by the qualitative description methodology described by Sandelowski (2000). Qualitative description allows the study to stay close to the woman's voice as it does not theorise beyond the data. Nonetheless, it allows for some interpretation of the data (Sandelowski, 2010).

Participants were recruited by advertising amongst members of a Japanese community group based in one centre of New Zealand. Only women who had given birth within the last three years of the date of the interviews, or the date of the focus group session, were invited to participate; the aim being to record recent birth experiences.

Two methods of data collection were used. First, nine individual interviews were undertaken to hear the women's stories and to seek their perspectives through their own personal narratives. Building on the interview findings, the researcher further discussed the issues raised with four other women in a subsequent focus group.

The data were analysed using a thematic analysis process outlined by Braun and Clarke (2006). This was a fundamental method used to organise and describe the data, and search for themes or patterns following the reading and re-reading of the transcriptions, and generating initial codes (Braun \& Clarke, 2006). It enables the researcher to stay close to the data and to identify the 
explicit meanings of the data through an inductive data-driven approach while maintaining a qualitative descriptive approach to the study.

Ethical approval for the study was given by the Otago Polytechnic Research Ethics Committee (ETHICS 470). This included consultation with the Kaitohutohu in relation to any potential impact the findings might have for Māori in New Zealand.

\section{FINDINGS}

\section{Demographics}

The ages of the women ranged from 32 to 42 years with an average age of 37 years. The women had lived in New Zealand for a period of between two and 19 years with an average time of 10 years. One woman's most recent education was at a high school, while all the other women continued their academic learning in universities or colleges. Eight of the women studied at universities in New Zealand. The women also had a variety of job experiences in New Zealand. These included working as a translator, a caregiver, and a university tutor.

Eight of the women had one child and five women had two to four children; all of whom were born in New Zealand. For their most recent birth, all of the women chose the hospital as the place to have their babies. Ten women gave birth vaginally and three women had non-elective caesarean sections.

\section{Maternity care in New Zealand compared to Japan}

While recalling their birth experiences, the women identified several differences between New Zealand and Japan in terms of maternity care. Although none of the participants had given birth in Japan, their expectations were often based on their knowledge of Japanese maternity care. This knowledge was shaped by their reading of Japanese books and magazines, and conversations with friends, siblings, and their mothers in Japan.

Key differences in pregnancy care in New Zealand noticed by the women, included fewer ultrasound scans and blood tests; recommendations to take more supplements; and key diet changes such as avoiding raw food during pregnancy. All the participants commented on the contrast in approach to weight management between the two countries, comparing New Zealand's low key approach to the strict weight checks which happen in Japan.

\begin{abstract}
"What I was happy about giving birth here was that there was no weight management. I gained $14 \mathrm{~kg}$ in the end... I was checking my weight by myself. I had been reading Japanese magazines casually, and they said the weight gain should be less than $8 \mathrm{~kg} . .$. . My midwife told me that it was not to worry. I wondered but I was relieved." (Participant 11)
\end{abstract}

Most of the women looked favourably on the New Zealand weight management care, whereas a minority were so worried that they recorded their weight themselves. Likewise, they generally enjoyed the New Zealand care, but they felt that something was missing at times.

\section{"[At check-ups] I thought it was not long enough and wondered if it was really okay only with that at the beginning... It was quite different from Japanese check-ups [which I had when I went back to Japan]." (Participant 8) \\ "I thought a little that I wanted to be taught more. I asked questions, but the answer was just, 'Don't worry, don't worry'." (Participant 7)}

There were clear differences in after birth care. Following birth in
Japan, women are recommended to have a long rest. How quickly women started moving after birth in New Zealand surprised most of the Japanese women. Having a shower soon after the birth is an example.
"I was told, 'Have a shower' [soon after the birth]. After the shower, the midwife said, 'Let's go to the room', so I walked... I thought 'Are you serious?' I was okay, but I was amazed." (Participant 4)
"What I was surprised about was, well... I was told to have a shower soon. I wondered whether this was okay, and said that I wouldn't, but I was told to have a shower soon... I was afraid a little, but the midwife said that I would be okay. I think I would not have been told to have a shower on the day of the delivery if I had been in Japan... I said that I would be okay without shower, but the midwife said that it would be good. Then I said that I was afraid to have a shower, but again she said that I would be okay... It was not an order, but she urged me. So I thought, 'Okay, if you say so strongly'. Then I had a very quick shower fearfully." (Participant 6)

In Japan, showering and moving around following birth are restricted to avoid an unbalanced pelvis. It is believed that being vertical and making physical movements affect the pelvis closing and lock the pelvis into an unbalanced or opened condition, resulting in backache and other problems (Kawana \& Matsubara, 2004; Okutani, 2009). Using eyes (e.g. light shining directly into the eyes, reading, watching) and using heads (e.g. thinking) are also thought to affect the pelvis closing following birth. Showering and being lightly clothed are not recommended in order to avoid bie - chill or coldness - into the "opened" body of the postpartum woman (Nakamura, 2012).

\section{Key differences in pregnancy care noticed by the women, included fewer ultra-sound scans and blood tests; recommendations to take more supplements; and key diet changes such as avoiding raw food during pregnancy.}

The most concern arose from the lack of regular ultrasound scans women were offered during their pregnancy. Ultrasounds are performed at every check-up in Japan while only one or two ultrasounds are offered through a normal pregnancy in New Zealand. Some of the women accepted this passively even though they would have preferred more, while others tried to convince their midwives to order more ultrasounds for them.
"I felt ultrasound should have been done every month. My friends had it every month in Japan and so did my sister, so I thought I would be able to do so, but it was only a few times in total... I asked to give me the chance once a month, but I was told not to take it so often... I was worried about my baby a lot. Those caused me a dilemma." (Participant 6)

In the focus group, the women did not appear to be satisfied with the number of ultrasounds either. Therefore, the researcher asked whether they knew why they only had a few ultrasounds in New Zealand.

"I hear there are more ultrasound scans in Japan. It is very few here, isn't it?... I wish [I had had ultrasounds] more often..."(Participant 11) 
"I had one additional ultrasound since my baby stopped moving. But I still wondered whether it was seriously okay because the number was much fewer than in Japan. I also became anxious, so I asked to have one more." (Participant 13)

"I did, too. My midwife told me that she would need a reason to ask for another ultrasound for me. So, she said that she would write a letter saying that she could hear the baby's heart beat, but it was slower than last time. Then I had an ultrasound at last. Oh, I remember. I couldn't see my baby's face at the previous scan, so I said, 'I really want to see the face, 'and she did that for me." (Participant 10)

"I also told my midwife that I wanted to do it one more time, but she told me, 'There have not been any problems. Also, they (ultrasonographers) are probably busy, so you would not get an appointment.' (Participant 11)

Interviewer: "You only had a few ultrasounds in New Zealand while women have an ultrasound at every check-up in Japan. Have you ever thought why it is different?"

"I have never thought about that." (Participants 10 and 11)

"I thought it was because they didn't have enough equipment [in New Zealand]." (Participant 13)

"I wondered if it was because they were not strict." (Participant 10)

"It's no problem not to see like that." (Participant 11)

"Are there any reasons?" (Participant 13)

Interviewer: "So, were you just thinking that you only received a few ultrasounds without any special reasons [in New Zealand]?"

"Yes, that's exactly like New Zealand." (Participant 11)

"I just thought, 'It is relaxed here. They don't check weight, either'. "Right?" (Participant 10)

"... Here midwives do not measure mother's belly, either.

They do not do anything." (Participant 13)

Their answers showed that their ideas were based on their image of New Zealand and the care, rather than the effect, risk or evidence for obstetrically appropriate frequency of ultrasound screening. In other words, they did not receive or seek any detailed reasons or explanations as to the effective use of ultrasounds from their midwives and doctors, although many of the women obviously struggled with this issue.

\section{Language and communication}

The women looked for reassurance to calm their anxiety from Japanese books about birth, preferring these for getting information. This meant that pamphlets and books in English offered by the midwives were seldom read, even though the women could read English well. One woman who had taught classes in a New Zealand university said:

"I researched about pregnancy for myself. I was worried because it was my first pregnancy. I had to learn about birth from nothing. I looked around and read a lot of books... Those were all in Japanese. English books were also given to me, but I thought it would take me a year to read." (Participant 8)

One woman also found the contents of the English books unhelpful.

"I learnt about pregnancy very much. They were mainly in Japanese, Japanese books. I also read books here a little bit, but there were some parts I did not understand. I wonder... I felt it was different, so I was reading Japanese books. I asked [my family] to send them from Japan and I borrowed from Japanese mothers here." (Participant 6)

None of the women mentioned problems with their English in daily life and they were confident about their fluency in the English language. However, some of the women worried about their understanding of English during their pregnancy and birth, particularly the medical terms.

"I considered having the baby in Japan. I was worried about medical English. I could communicate [in English] in daily life, though. You know, medical words. I would have to go to the hospital and to see doctors for 10 months of the pregnancy. I was worried about miscommunication. I would not have been happy if doctors could not clearly understand what I was saying." (Participant 6)

\section{Their answers showed that their ideas were based on their image of New Zealand and the care, rather than the effect, risk or evidence for obstetrically appropriate frequency of ultrasound screening.}

Even a woman who had lived in New Zealand for 20 years, since entering a university, commented on the language barrier, especially about understanding the more technical terms. A few of the women experienced some difficulties using English, particularly during their labour.

"I became not able to speak in English [during the labour]... English never came out." (Participant 8)

"When an epidural was going to be used, I did not have any problem or anxiety until I heard technical terms. An anaesthetist asked me many questions... The questions were too specialised and I couldn't understand them, but my partner was with me and explained for me [in English]. So I signed the form for the time being supposing it wouldn't be any problem." (Participant 12)

One woman said, "I was thinking how much I wanted a Japanese midwife here during my pregnancy" (Participant 6). Communicating in her mother tongue was very important for her. She also believed that language influenced the way of thinking and contributed to a deeper understanding. She needed a midwife for her pregnancy and birth who could understand how she was feeling and with whom she could share her own cultural perspective. Another woman provided an example of how communication is different between how she, as a Japanese woman, communicates, and how her New Zealand care providers communicated.

"I said I couldn't sleep and was suffering, but the specialist did not recognise that I was having a hard time... The midwife had probably not realised that, either. I might not have told them the entire truth... The midwife told me that she saw me having the maternity glow... I was thinking it was really different from how I was feeling. It seemed my pain wasn't obvious on the outside. I knew that they didn't see that. I just said, 'Really? I am really painful. I am not like that.' [in a small voice]. That's all I said... I should have told them about my pain more, but I didn't. Communication was in English, so I couldn't get the message across. Wouldn't you agree that they don't work unless you 
push very much? That might have been a problem. It was painful, indeed." (Participant 9)

Not only were there problems with language, but also with different communication styles. For example, Yoshida et al. (1997) report that Western tools for assessing postnatal depression do not work for Japanese women, who have different ways of expressing their feelings. Characteristically, Japanese women would rather not express how they are feeling, but their feelings find expression in physical conditions.

\section{DISCUSSION}

\section{Japanese "strict care" and New Zealand "relaxed care"}

These Japanese women described New Zealand care as relaxed, "no problem", or "take-it-easy" care, while recognising Japanese care as strict, fussy, thorough, more worried or concerned care. This perception was based on the practice by both obstetricians and midwives, for example, of not weighing pregnant women regularly in New Zealand. By contrast, the women knew that in Japan their weight would be assessed at every pregnancy check-up. These differences were considered by the women to be reflective of the differences between the two cultures and the two countries' national characteristics.

Generally, the women enjoyed the New Zealand "take-it-easy" approach. However, they sometimes wanted more advice and more detailed care, and sometimes felt anxious about the care they received. In other words, the women felt that Japanese care provided too much, and New Zealand care offered too little. As a result, they were not completely satisfied with their maternity care in New Zealand.

\section{Attitudes to ultrasound}

Of all the differences in care between the two countries the approach to ultrasound screening was the most significant issue for the participants of this study, who considered that they should have had more ultrasound scans. When coupled with the absence of regular weight checks, the women perceived their pregnancy care in New Zealand as lax management.

It has been globally recognised that the frequent, routine use of ultrasound scanning does not improve the health of the mother or baby, nor change the behaviour of pregnant women and the quality of birth outcomes (Bricker, Neilson, \& Dowswell, 2009; Ewigman et al., 1993). As such there is no evidence of benefit in providing all pregnant women with frequent and routine ultrasounds in terms of effect or cost (Neilson \& Grant, 1989; Wagner, 2002). Despite the lack of evidence the prevalence of ultrasounds in Japan has not decreased, with an ultrasound scan performed at every check-up and considered to be essential care by health professionals and women in Japan (Suzui, 2005). This may be due to cultural differences or for defensive practice reasons but also demonstrates the potential for the clinician's judgement and skills to be undermined by technology with no proven improvement to outcomes.

Yet, the focus of this study was not the frequency and appropriateness of ultrasounds but the differences in expectations that are driven by different cultural backgrounds. These Japanese women in this study did not recall information or discussions explaining that the limited number of ultrasounds offered within the New Zealand health system was a practice based on evidence. It is not clear if the care providers were aware of the level of these Japanese women's dissatisfaction with the number of ultrasounds. However, it is possible that had they been provided with more information about the benefits and issues concerning ultrasounds, their feelings of dissatisfaction may not have been so strong. This finding was specific to the Japanese women in this study but may also be an issue for others. These findings demonstrate there is room for improvement, and a need to ensure evidence-based rationale when midwives discuss ultrasound with women.

Suzui (2005) suggests that Japanese women do not gain a sense of ease and happiness only with the image on the screen of ultrasounds; rather, their psychological comfort is obtained through the professionals' explanations and comments about the development of the baby in conjunction with the ultrasound. Therefore, it is possible that improved communication between the women and their care providers (around fetal development trimester by trimester [or even week by week] and the significance and reassurance of adequate fetal movements) can make up for the women's desire for more ultrasounds, as well as offering the women information concerning New Zealand's evidence-based approach to ultrasound use.

\section{The issues of communication - English language}

The Japanese women's experiences appeared to be influenced by their ability to communicate with their non-Japanesespeaking care providers. In a study of immigrant women in Australia (Small, Rice, Yelland, \& Lumley, 1999), the women's English language ability was found to be strongly associated with their level of satisfaction with their maternity care.

\section{Most of the Japanese women in the current study did not report feeling stressed when communicating in English in daily life, but they did experience difficulties with the technical language used throughout pregnancy and labour.}

Most of the Japanese women in the current study did not report feeling stressed when communicating in English in daily life, but they did experience difficulties with the technical language used throughout pregnancy and labour. Furthermore, they found communicating in English all the time tiring and frustrating, especially during labour and when they were exhausted taking care of babies after birth. When people are stressed, they often find it difficult to respond appropriately to what they are asked, or to understand. Therefore, the language barrier did affect their level of satisfaction with their care and birth outcomes. Even when the women were calm during pregnancy, how deeply they could communicate and understand about their care was a concern because they avoided reading the English language maternity information given to them. As Yeo, Fetters, and Maeda (2000) suggest, care providers should not expect Japanese to read and understand written information, however well they appear to understand English.

Further, the interpretation by partners during labour and birth may not always reflect accurately the information given, or convey accurately the woman's responses. Much information is possibly missed in their translation. For example, one partner in this study attempted to translate the anaesthetist's explanations about an epidural from English into simpler English. The partner was attempting to make the woman feel at ease, but left out the more 
complicated clinical details. So care providers may be misled by the initial verbal responses of women. When there is a need to talk to women during labour and birth, it is important to sensitively check and recheck understandings and feelings. This includes verifying the woman's choices in an unhurried manner and involving partners and interpreters for those who are not native English speakers.

\section{Passive attitudes}

In addition to the language difference, the women's expectations and experiences are potentially related to particular Japanese ways of thinking and communicating (Tachibana, 2009). Japanese value saying nothing, and reading the atmosphere of someone's emotion and messages between words or without words (Kenmochi, 1992; Okoshi, 2005). Also, hikaeme - humility, modesty, or not sharing opinions - is considered a virtue in Japanese culture. These Japanese characteristics have also been discussed in the theory of dependency, amae (Doi, 1971). Within the highly homogeneous society of Japan, people can expect other people to guess their intentions and implications based on this mutual dependency, so they may take a passive attitude, but this communication approach does not work well in the West.

Japanese society is also known as a collectivism or mutual collaboration in contrast to the individualism or mutual independence found in many Western societies (Fukasaku, 1971; Okoshi, 2005). With such a conformist Japanese worldview, women could feel more comfortable agreeing with other people and following their advice rather than arguing their own point of view in a relationship. However, this does not mean that people are necessarily happy with the choice and the result. The women in this study hesitated to ask questions and often did not express exactly what they were feeling or wanting, expecting the care providers to read their wishes without these being stated. This may mean that Japanese women defer to their care providers' opinions, even when these go against what they think should happen. Thus, doing what they consider the "polite" thing to do, but without the complementary, unspoken "reading between the lines", consideration by the caregivers of the needs and choices of the woman. These attitudes contribute to the lack of understanding and the feeling of dissatisfaction with their care.

\section{The cultural inheritance of humility and respect apparent within Japanese society is clearly at odds with that of New Zealand society. This potentially increases the difficulties for midwives providing care to Japanese women within the New Zealand model of maternity care.}

The passive attitude of the Japanese is frequently discussed in health and medical fields and, in terms of doctor-patient relationships within Japan (Nishiyama, 2009; Sameshima, 2010). Many patients or clients trust doctors; they tell them "I will leave it to you" and entrust their treatment to doctors. This phrase was also stated by the women in this study when it came to decision making for pain relief and other care choices. Leaving the care of their bodies and babies up to doctors, accepting professional-centred care, and the medicalisation of women's bodies in maternity care and reproductive health sectors - all these have also been criticised in contemporary Japan (Kashiwaba, 2008; Misago, 2004; Namihira, 2005). These tendencies are a contrast to the expectations inherent within the partnership model of maternity care characterised by women-centred care, informed decision making and reciprocity (Guilliland \& Pairman, 2010). The cultural inheritance of humility and respect apparent within Japanese society is clearly at odds with that of New Zealand society. This potentially increases the difficulties for midwives providing care to Japanese women within the New Zealand model of maternity care.

On the other hand, these Japanese women may be considered to be easy to care for because they seldom require in-depth discussion and will follow advice without question. Yet, this may result in increased distress and dissatisfaction for the woman. This is clearly a problem for women who have a different culture from the dominant culture. In Small et al.'s (1999) study, when an immigrant woman made a decision that coincided with the dominant care in the West - having a shower after birth - but opposite to her native country's birth culture, her midwife told her, "You're a good girl" (p. 97). This midwife did not push her opinion with respect for the woman's culture, but by complimenting the woman's choice, she sent the message that she preferred her to act in accordance with her view.

The Japanese women in this study also described similar situations. Their focus seemed to be on being dutiful as well as not hurting the care provider's feelings. The "good" relationship is more important for Japanese women than asserting their own beliefs. For such women, the advice and opinions of care providers are very influential. Therefore, the care providers need to carefully recognise the woman's communicative background and reflect on how they are providing the care for her.

\section{STRENGTHS AND LIMITATIONS}

This was a small study undertaken in one geographical area of New Zealand, thus the findings can not be generalisable to the larger total population of Japanese women birthing in other areas of New Zealand or elsewhere. Despite this limitation, the women freely shared their experiences, shedding light on some of the issues that other immigrant women might also experience in terms of different cultures and midwifery care. These women faced language challenges and cultural differences resulting in an inability to genuinely express their aspirations and concerns. Importantly, this study highlights the need to find ways to bridge the cultural and language gaps when sharing information and seeking true consent for care in the social and cultural event that is childbirth.

\section{CONCLUSION}

This study has examined the birth experiences of 13 Japanese women living in one New Zealand centre. All Japanese are not the same, so care needs to be individualised irrespective of race and cultural differences. Nonetheless, within this small group the women were shown to have common experiences around aspects of care such as ultrasound scans and weight checks, which caused them some distress and anxiety. These feelings were exacerbated by the challenges they had with the language and communication.

What this study offers are insights into some of the cultural expectations of Japanese women and their reluctance to challenge the opinions and decisions of their care givers. It also highlights the difficulty of conversing in a language other than your own in stressful and emotional events such as labour and birth. The establishment of a trusting relationship consistent with the New Zealand partnership model has the potential to support open communication. Understanding the different cultural values should help midwives support Japanese women to discuss their 
emotions and desires for their birth experience. Also, midwives' understanding will enable the women to make better informed decisions and feel supported by the system rather than alienated by it.

\section{ACKNOWLEDGEMENTS}

We are grateful to the Japanese women who generously gave their time and shared their experiences for this study. This study received financial support from an Otago Polytechnic Postgraduate Grant.

\section{REFERENCES}

Braun, V., \& Clarke, V. (2006). Using thematic analysis in psychology. Qualitative Research in Psychology, 3(2), 77-101.

Bricker, L., Neilson, J. P., \& Dowswell, T. (2009). Routine ultrasound in late pregnancy (after 24 weeks' gestation). Cochrane Database of Systematic Reviews 2008, (4). doi: 10.1002/14651858.CD001451.pub3

Callister, L. C. (1995). Cultural meanings of childbirth. JOGNN, 24(4), 327-331.

Callister, L. C., Semenic, S., \& Foster, J. C. (1999). Cultural and spiritual meanings of childbirth: Orthodox Jewish and Mormon women. Journal of Holistic Nursing, 17(3), 280-295. doi: 10.1177/089801019901700305

Cheung, N. F. (2002). The cultural and social meanings of childbearing for Chinese and Scottish women in Scotland. Midwifery, 18(4), 279-295. doi: $10.1054 /$ midw.2002.0328

Doi, T. (1971).「甘え」の構造 [The anatomy of dependence]. Tokyo, Japan: Koubundou.

Ewigman, B. G., Grane, J. P., Frigoletto, F. D., LeFevre, M. L., Bain, R. P., McNellis, D., \& the RADIUS Study Group. (1993). Effect of prenatal ultrasound screening on perinatal outcome. The New England Journal of Medicine, 329(12), 821-827. doi: 10.1056/ NEJM199309163291201

Fukasaku, M. (1971). 日本文化抢よび日本人論 [Japanese culture and theory of the Japanese]. Tokyo, Japan: Sanichi Shobo.

Guilliland, K., \& Pairman, S. (2010). The Midwifery Partnership: A model for practice. Wellington, New Zealand: Victoria University of Wellington.

Jordan, B. (1980). Birth in four cultures: A crosscultural investigation of childbirth in Yucatan, Holland, Sweden, and the United States (2nd ed.). Montréal, Canada: Eden Press Women's Publications.

Kartchner, R., \& Callister, L. C. (2003). Giving birth: Voices of Chinese women. Journal of Holistic Nursing, 21(2), 100-116. doi: 10.1177/0898010103021002002

Kashiwaba, M. (2008). 看護師教育における母性看護学の検討：妊 産婦支援の視点から [The study of maternal care in nursing education: From the view-point of support for pregnant and nursing women]. Hattatsu Ningengaku Ronsou, 11, 89-96.

Kawana, H., \& Matsubara, H. (2004). 子どもがすくすく育つに は：身体のしくみの話 [Child development: The function of the body]. Tokyo, Japan: Constitution Research Institute.

Kenmochi, T. (1992).「間」の日本文化 [Japanese culture of "ma (space, room, pause, interval, time, luck, chance or timing)"]. Tokyo, Japan: Chobunsha.

Liamputtong, P., \& Naksook, C. (2003). Perceptions and experiences of motherhood, health and the husband's role among Thai women in Australia. Midwifery, 19, 27-36. doi: 10.1054/midw.2002.0333

Matsuoka, E. (1985). 出産の文化人類学：儀礼と産婆 [Cultural anthropology of childbirth: Ritual and midwives]. Tokyo, Japan:Kaimeisha.
Misago, C. (2004). 昔の女性はできていた：忘れられている女性 の身体に “在る” 力 [Things women in the past could do: The forgotten power of "existing” in women's bodies]. Tokyo, Japan: Takarajima-sha.

Nakamura, S. (2012). 冷えを科学する [Study hie scientifically]. Japanese Journal for Midwives, 66(11), 904-910.

Namihira, E. (2005). からだの文化人類学：変貌する日本人の身体 観 [Cultural anthropology of the body: Changing perspectives of the Japanese body]. Tokyo, Japan: Taishukan.

Neilson, J., \& Grant, A. (1989). Ultrasound in pregnancy. In I. Chalmers, M. Enkin \& M. J. N. C. Keirse (Eds.), Effective care in pregnancy and childbirth (pp. 419-439). Oxford, England: Oxford University Press.

Nishiyama, K. (2009). ポリフォニーの時代を迎える医療現場：

「㧍まかせ医療」を越えて [The medical scene in a polyphonic era: Overcoming "Omakase (leaving it to someone) medicine"]. Japanese Journal of Nursing, 61(13), 88-91.

Okoshi, A. (2005). 日本及び日本人 [Japan and the Japanese]. Tokyo, Japan: Choeisha.

Okutani, M. (2009). 新.お産本：すべてのお産がベストなお産 [The new birth book: Every birth is the best birth]. Itoman, Japan: Kamestore.

Sameshima, T. (2010). 現代医療における医師：患者関係の問題 点とその克服 [Doctors in modern medicine: Problems concerning the relationship with patients]. Japanese Journal of Group Dynamics, 27, 33-61.

Sandelowski, M. (2000). Focus on research methods: Whatever happened to qualitative description? Research in Nursing and Health, 23(4), 334-340.

Sandelowski, M. (2010). What's in a name? Qualitative description revisited. Research in Nursing and Health, 33, 77-84.

Small, R., Rice, P. L., Yelland, J., \& Lumley, J. (1999). Mothers in a new country: The role of culture and communication in Vietnamese, Turkish and Filipino women's experiences of giving birth in Australia. Women \& Health, 28(3), 77-101.

Statistics New Zealand. 2013. New Zealand has more ethnicities than the world has countries, 2013 census. Retrieved from http://www.stats.govt. nz/Census/2013-census/data-tables/totals-by-topic-mr1.aspx

Suzui, E. (2005). The emotional and physical experience of pregnancy: A comparison of pregnant women who are examined using ultrasound and those who are not. Journal of Kawasaki Medical Welfare Society, 15(1), 85-93.

Tachibana, H. (2009). 日本人の価値観 [The Japanese worldview]. Tokyo, Japan: Perikan-sha.

Wagner, M. (2002). WHO勧告にみる望ましい周産期ケアとそ の根拠 [Desirable perinatal care and the evidence according to WHO's recommendation]. Osaka, Japan: Medica Shuppan.

Yeo, S., Fetters, M., \& Maeda, Y. (2000). Japanese couples' childbirth experiences in Michigan: Implications for care. Birth, 27(3), 191-198.

Yoshida, K., Marks, M. N., Kibe, N., Kumar, R., Nakano, H., \& Tashiro, N. (1997). Postnatal depression in Japanese women who have given birth in England. Journal of Affective Disorders, 43, 69-77.

\section{Accepted for publication February 2015}

Doering, K., Patterson, J., Griffiths, C. (2015). Experience of the New Zealand maternity care system by a group of Japanese women in one centre. NZCOM Journal 51, 5-10. http://dx.doi.org/10.12784/nzcomjn151.2015.1.5-10 